\title{
Critical Evaluation of Emergency Peripartum Hysterectomy Cases in a Tertiary Care Centre in Eastern India
}

\author{
Jhantu Kumar Saha ${ }^{1}$, Pallab Kumar Mistri², Nandini Sinha ${ }^{3}$ \\ ${ }^{1}$ Department of Obstetrics and Gynaecology, Medical College, Kolkata, West Bengal, India. ${ }^{2}$ Department of Obstetrics \\ and Gynaecology, Medical College, Kolkata, West Bengal, India. ${ }^{3}$ Department of Obstetrics and Gynaecology, Medical \\ College, Kolkata, West Bengal, India.
}

\section{ABSTRACT}

\section{BACKGROUND}

Emergency Peripartum Hysterectomy (EPH) is one of the most dramatic operations in modern obstetrics, performed only when all conservative measures have failed to achieve homeostasis in the setting of massive postpartum haemorrhage (PPH). We wanted to determine the incidence, indications, and outcomes, of EPHs done at Medical College \& Hospital, Kolkata between January 1, 2017 and December 31, 2017.

\section{METHODS}

A retrospective review of all cases of EPH over a 12-month period was done. EPH was defined as hysterectomy performed for PPH unresponsive to other treatments within 24 hours of delivery. Relevant information was extracted from the hospital records and operation notes.

\section{RESULTS}

The highest proportion of women who had EPH was in the age-group 25 - 30 years (51.1\%). Majority of the subjects was from rural areas (61\%). Most patients had no formal education (51.6\%). Nearly two-thirds (58.1\%) of the husbands had an undergraduate education and belonged to middle socio-economic strata (52\%). There were 31 EPHs performed among 13490 deliveries within the study period, giving a rate of 2.29 per 1000 deliveries. Maternal mortality was $13 \%(95 \%$ Confidence Interval [CI] 1.16-24.8) and perinatal mortality rate was 35.5\% (18.652.3). The most common presentation was bleeding per vagina (80.6\%) and severe pallor (52\%). Main indications included placenta accreta (38.2\%), placenta previa (32.3\%), placenta percreta (12.9), uterine atony (3.2\%), abruptio placentae $(3.2 \%)$, broad ligament haematoma $(3.2 \%)$, uterine rupture $(3.2 \%)$ and uncontrolled PPH $(3.2 \%)$.

\section{CONCLUSIONS}

The rate of EPH in our institution is high. Abnormal placentation was the most common indication for $\mathrm{EPH}$, requiring a total hysterectomy in most cases. A previous CS was an important pre-operative risk factor for abnormal placentation and in particular for pathological adherence of the placenta. Post-operative shock was associated with poor outcome. EPH in our centre remains associated with a high incidence of morbidity and mortality as our center is an apex referral tertiary centre.

\section{KEY WORDS}

Peripartum Hysterectomy, Post-Partum Haemorrhage, Placenta Accreta
Corresponding Author: Dr. Pallab Kumar Mistri, Rishi Arabindapally, 110 KM, Roychowdhury Road, P. O. South Jagaddal, P. S. Sonarpur, Kolkata-700151,

West Bengal, India. E-mail: pallab1012@gmail.com

DOI: $10.14260 /$ jemds/2019/742

Financial or Other Competing Interests: None.

How to Cite This Article:

Saha JK, Mistri PK, Sinha N. Critical evaluation of emergency peripartum hysterectomy cases in a tertiary care centre in Eastern India. J. Evolution Med. Dent. Sci. 2019;8(46):3422-3426, DOI: $10.14260 /$ jemds/2019/742

Submission 15-09-2019, Peer Review 30-10-2019,

Acceptance 06-11-2019,

Published 18-11-2019. 


\section{BACKGROUND}

Emergency postpartum hysterectomy (EPH) is defined as hysterectomy performed within 24 hours of vaginal or caesarean delivery. It is an uncommon obstetric procedure, usually performed as a life-saving last resort to save the maternal life after childbirth in cases of intractable obstetric haemorrhage.1,2 It was first proposed in 1869 but with no desirable results. However, seven years later (1876), the first caesarean subtotal hysterectomy was carried out successfully by Italian obstetrician Dr. Eduardo Porro, ${ }^{3}$ with favourable outcome for both the mother and the baby.

In modern obstetrics, the overall incidence of EPH is $0.02 \%-0.05 \%{ }^{4}$ Despite its life-saving capacity, EPH is however, associated with high morbidity and mortality, and negatively affects women's future fertility. Consequently, such crucial disadvantages need to be reflected upon when considering individualized treatment. Severe postpartum haemorrhage was reported to occur in $6.7 / 1,000$ deliveries worldwide. ${ }^{5}$ It is one of the leading causes of maternal mortality and morbidity and represents the most challenging complication in a delivery patient. Abnormal placentation has now become a bigger cause than uterine atony and rupture for EPH. Studies have consistently demonstrated that previous CS increases the risk of EPH and abnormal placentation is associated with a previous uterine scar. It is also observed that the risk of EPH increases with the number of previous CS. Other factors that have been associated with EPH include advanced maternal age, multiparity, multiple gestations, and gestational diabetes. ${ }^{5}$

The incidence of EPH is higher in developing countries, compared to the developed nations. ${ }^{5}$ This can be attributed to better antenatal care in the developed economies, with better knowledge of patients regarding family planning along with availability of better obstetric care supplemented by modern facilities like uterine artery embolisation. The aims and objectives were to assess most dominant factor/factors leading to EPH and to evaluate modifiable factor/factors among the dominant factors to prevent such outcome in future.

\section{METHODS}

Medical records of patients who underwent EPH between January 1, 2017 and December 31, 2017 (i.e. 12 months) were evaluated retrospectively. Medical information for those who were transported from affiliated clinics following caesarean or vaginal delivery for PPH was collected manually from patient records at their respective clinics. Following Institutional Ethics Committee (IEC) approval, we conducted a retrospective analysis of all cases of EPH performed at Medical College \& Hospital, Kolkata. EPH was defined as hysterectomy performed for PPH unresponsive to other treatment within 24 hours of delivery. ${ }^{6}$ All operations in this study were obstetrical haemorrhage emergencies judged to be life-threatening by qualified obstetricians. EPH was carried out within the first 24 hours of the postpartum period. Maternal characteristics, including maternal age, parity, previous caesarean section (CS), and mode of delivery were obtained. Information pertaining to indications for EPH, type of hysterectomy, operating time, estimated preoperative blood loss, intraoperative blood loss, pre-operative haemoglobin values $(\mathrm{Hb})$, pre - and postoperative complications, need for transfusion, and postoperative hospitalization days were collected from medical records. Evidence of intraoperative complications and the occurrence of surgical mishaps were obtained from operation records. Postoperative severe anaemia was defined as a haemoglobin concentration of $<7 \mathrm{~g} / \mathrm{dL}$, and postpartum haemorrhage as blood loss of $\geq 500 \mathrm{~mL}$ following vaginal delivery or $\geq 1000$ $\mathrm{mL}$ or more following Caesarean section. ${ }^{7}$ Urinary tract infection referred to urinary symptoms with a positive urine culture. Postoperative pyrexia referred to a rectal temperature of $\geq 38.5^{\circ} \mathrm{C}$, persisting for more than two postoperative days exclusive of first 24 hours following delivery. Postoperative counselling was carried out for all the cases before they were discharged to help patients accept the loss of menstrual function and childbearing ability that inevitably accompany this procedure. The data obtained from the patients or their relatives, as well as from their case notes, were recorded in a standard form. Quality control was done by ensuring that data collection was carried out before the patients were discharged.

\section{Statistical Analysis}

The data that were obtained were analysed using Graph Pad Prism 5 (Graph Pad Software Inc. CA, USA). Numerical data were analysed using mean \pm standard deviation. Categorical data were presented as frequencies and percentages. Chisquare test was used to compare groups for significant differences. The contribution of the sociodemographic factors to the incidence of the procedures, and of the indications for the procedure on the management options, were estimated using chi-square test, and a $\mathrm{P}$ value of $<0.05$ was taken as significant. The odds ratio and $95 \%$ confidence intervals were also determined where appropriate.

\section{RESULTS}

During the period, there were 31 EPHs performed among 13490 deliveries within the study period, giving a rate of 2.29 per 1000 deliveries. The demographics of the study population are shown in Table 1 . The mean age of the patients was $26.26 \pm 4.9$ years. The highest proportion of women who had EPH was in the age-group 25 - 30 years (51.1\%). The sample cohort comprised of women from rural areas (61\%). Most patients had no formal education (51.6 $\%)$, however, most (58.1\%) of the husbands were a minimum of undergraduate and belonged to middle class socio-economic strata (52 \%). Table 2. Shows the characteristics of study cohort on initial presentation. The mean SD estimated gestational age at delivery was $35.7 \pm$ 5.67 years. About $58.1 \%$ subjects presented at term (40 weeks). Sonography revealed high incidence of abnormal placentation (64.5\%), in which placenta previa (54.8\%) was common in particular. 0 positive blood group was highly prevalent among the subjects (41.9\%), most patients had severe pallor (52\%) and bleeding per vagina $(80.6 \%)$ on initial examination. Table 3. Depicts indications for EPH in the study cohort. Abnormal placentation (83.8\%) was the 
leading cause requiring $\mathrm{EPH}$, among which placenta accreta (38.2 \%) was commonest variety. Other indications included placenta previa (32.3\%), placenta percreta (12.9), uterine atony $(3.2 \%)$, abruptio placentae $(3.2 \%)$, broad ligament haematoma (3.2\%), uterine rupture (3.2\%) and uncontrolled post-partum haemorrhage (3.2\%).

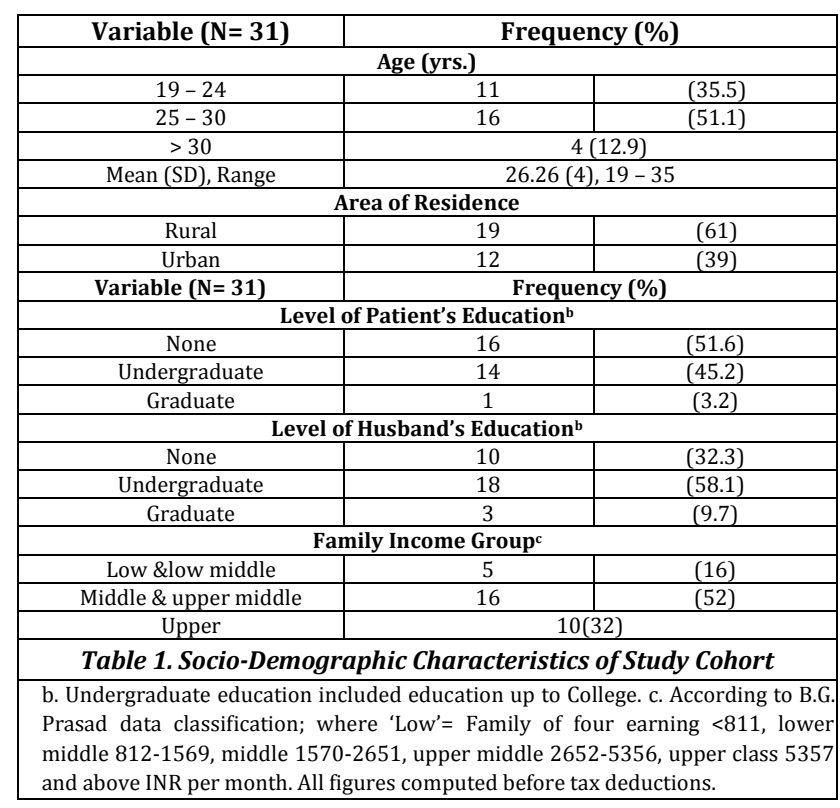

\begin{tabular}{|c|c|c|}
\hline Variable $(\mathrm{N}=31)$ & \multicolumn{2}{|c|}{ Frequency (\%) } \\
\hline \multicolumn{3}{|c|}{ Blood Group } \\
\hline AB positive & 1 & $(3.2)$ \\
\hline A positive & 7 & $(22.60$ \\
\hline B negative & 1 & $(3.2)$ \\
\hline B positive & 9 & (29) \\
\hline O positive & \multicolumn{2}{|c|}{$13(41.9)$} \\
\hline \multicolumn{3}{|c|}{ Sonographic Diagnosis } \\
\hline Placenta percreta & 1 & $(3.2)$ \\
\hline Placenta accreta & 2 & $(6.5)$ \\
\hline Placenta previa & \multicolumn{2}{|c|}{$17(54.8)$} \\
\hline None & \multicolumn{2}{|c|}{$11(35.5)$} \\
\hline Variable $(\mathrm{N}=31)$ & \multicolumn{2}{|c|}{ Frequency (\%) } \\
\hline \multicolumn{3}{|c|}{ Estimated Gestational Aged at Delivery } \\
\hline Mean (SD) & \multicolumn{2}{|c|}{$35.7(5.67)$} \\
\hline Term (40 weeks) & 18 & $(58.1)$ \\
\hline $35-39$ weeks & 1 & $(3.2)$ \\
\hline $29-34$ weeks & 6 & (19.3) \\
\hline $24-28$ weeks & 6 & (19.4) \\
\hline \multicolumn{3}{|c|}{ Bleeding per Vagina } \\
\hline No & 6 & $(19.4)$ \\
\hline Yes & 25 & $(80.6)$ \\
\hline \multicolumn{3}{|c|}{ Severe Pallore } \\
\hline No & 16 & $(52)$ \\
\hline Yes & 15 & (48) \\
\hline
\end{tabular}

Table 2. Characteristics of Study Cohort on Initial Presentation

b. Gestational age calculated from the woman's last menstrual period (LMP). c. Estimated by tongue pallor as an indirect estimate of anaemia at haemoglobin $<7$ $\mathrm{g} / \mathrm{dL}$.

\begin{tabular}{|c|c|}
\hline Variable (N= 31) & Frequency (\%) \\
\hline Uterine rupture & $1(3.2)$ \\
\hline Uncontrolled PPH & $1(3.2)$ \\
\hline Broad ligament haematoma & $1(3.2)$ \\
\hline Abruptio placentae & $1(3.2)$ \\
\hline Atonic uterus & $1(3.2)$ \\
\hline Abnormal placentation & $26(83.4)$ \\
\hline Placenta percreta & $4(12.9)$ \\
\hline Placenta previa & $10(32.3)$ \\
\hline Placenta accrete & $12(38.2)$ \\
\hline Table 3. Indications for Emergency Peripartum Hysterectomy in the \\
\multicolumn{2}{|c}{ Study Cohort } \\
\hline
\end{tabular}

\begin{tabular}{|c|c|c|c|c|}
\hline $\begin{array}{c}\text { Variable } \\
(\mathrm{N}=31) \text { Gravida }\end{array}$ & $\begin{array}{c}\text { Frequency } \\
\text { (\%) }\end{array}$ & $95 \%$ CI & $\begin{array}{c}\text { Mean (SD), } \\
\text { Range }\end{array}$ & $\begin{array}{c}\text { Median } \\
\text { (IQR) }\end{array}$ \\
\hline 1 & $1(3.2)$ & $0.5-16.2$ & \multirow{5}{*}{$\begin{array}{c}2.84(0.89) \\
1-5\end{array}$} & \multirow{5}{*}{$3(2-3)$} \\
\hline 2 & $11(35.5)$ & $21.2-53$ & & \\
\hline 3 & $12(38.7)$ & $23.7-56.2$ & & \\
\hline 4 & $6(19.4)$ & $9.2-36.3$ & & \\
\hline 5 & $1(3.2)$ & $0.5-16.2$ & & \\
\hline \multicolumn{3}{|c|}{ Parity } & \multirow{6}{*}{$\begin{array}{c}1.87(0.88) \\
0-4\end{array}$} & \multirow{6}{*}{$2(1-2)$} \\
\hline 0 & $1(3.2)$ & $0.5-16.2$ & & \\
\hline 1 & $10(32.3)$ & $18.5-49.8$ & & \\
\hline 2 & $13(41.9)$ & $26.4-59.2$ & & \\
\hline 3 & $6(19.4)$ & $9.2-36.3$ & & \\
\hline 4 & $1(3.2)$ & $0.5-28.8$ & & \\
\hline \multicolumn{2}{|c|}{ Mode of delivery } & \multirow{2}{*}{$0.5-16.2$} & \multirow{2}{*}{$\begin{array}{c}0.97(0.18), \\
0-1\end{array}$} & \multirow{2}{*}{$1(0-1)$} \\
\hline VD & $1(3.2)$ & & & \\
\hline $\begin{array}{c}\text { Variable } \\
(\mathrm{N}=31)\end{array}$ & $\begin{array}{c}\text { Frequency } \\
(\%)\end{array}$ & $95 \%$ CI & \multirow{2}{*}{$\begin{array}{l}\text { Mean (SD), } \\
\text { Range }\end{array}$} & \multirow{2}{*}{$\begin{array}{c}\text { Median } \\
\text { (IQR) }\end{array}$} \\
\hline CS & $30(96.8)$ & $83.3-99.4$ & & \\
\hline \multicolumn{3}{|c|}{ Previous CS } & & \\
\hline 0 & $2(6.5)$ & $1.8-20.7$ & \multirow{4}{*}{$\begin{array}{c}1.32(0.65) \\
0-3\end{array}$} & \multirow{4}{*}{$1(1-2)$} \\
\hline 1 & $18(58.1)$ & $40.7-73.5$ & & \\
\hline 2 & $10(32.3)$ & $18.5-49.8$ & & \\
\hline 3 & $1(3.2)$ & $0.5-16.2$ & & \\
\hline \multicolumn{3}{|c|}{ Previous VD } & \multirow{3}{*}{$\begin{array}{c}0.10(0.30) \\
0-1\end{array}$} & \multirow{3}{*}{$0(0-1)$} \\
\hline 0 & $28(90.3)$ & $75.1-96.6$ & & \\
\hline 1 & $3(9.7)$ & $3.3-24.9$ & & \\
\hline \multicolumn{3}{|c|}{ Previous DC } & \multirow{4}{*}{$\begin{array}{c}0.42(0.67) \\
0-2\end{array}$} & \\
\hline 0 & $21(67.7)$ & $50.1-81.4$ & & \multirow{3}{*}{$0(0-1)$} \\
\hline 1 & $7(22.6)$ & $11.3-39.8$ & & \\
\hline 2 & $3(9.7)$ & $3.3-24.9$ & & \\
\hline \multicolumn{3}{|c|}{ ANC Visits } & \multirow{3}{*}{$\begin{array}{c}3.26(1.89) \\
1-9\end{array}$} & \multirow{3}{*}{$3(2-4)$} \\
\hline$\leq 3$ & $21(67.7)$ & $50.1-81.4$ & & \\
\hline$>3$ & $10(32.3)$ & $18.5-49.8$ & & \\
\hline ANC & \multicolumn{2}{|c|}{ USG } & \multirow{4}{*}{$\begin{array}{c}2.29(1.63) \\
1-9\end{array}$} & \multirow{4}{*}{$2(1-3)$} \\
\hline (abdomen) & $25(80.6)$ & $63.7-90.8$ & & \\
\hline$\leq 3$ & $6(19.3)$ & $9.1-36.2$ & & \\
\hline$>3$ & & & & \\
\hline
\end{tabular}

Table 4. General Characteristics of Patients Undergoing Emergency Peripartum Hysterectomy

SD, Standard deviation; IQR, Inter-quartile range; CI, Confidence interval; CS, Caesarean section; VD, Vaginal delivery; DC, Dilatation \& Curettage; ANC, Antenatal care; USG, Ultrasound.

Table 4. Represents the general characteristics of patients undergoing EPH. The median gravida and median parity were 3 (range 1 - 5) and 2 (range 0 - 4), respectively. About twoquarters $(61.2 \%)$ had a given birth 3 or more times prior to EPH. Proportion having gravida 3, 4, 5 was $38.75 \%, 19.4 \%$ and $3.2 \%$ respectively. Most patients (41.9\%) had a parity of 2.2 patients had a history of VBAC. With respect to mode of delivery, $96.8 \%$ and $3.2 \%$ had caesarean section and vaginal delivery, respectively. One subject with uterine rupture also had an initial exploratory laparotomy, followed by EPH. Median number of antenatal visits were 3 (range 2 4) and antenatal sonography was $1(0-1)$. Table 5 . Summarizes the operative \& post-operative details of patients who had EPH. Nearly two-thirds (67.7\%) of all the EPHs performed were in initially unbooked. The decision of performing total $(80.6 \%)$ or subtotal $(16.1 \%)$ hysterectomy was influenced by the patient's condition. About one-third of the women (35 \%) experienced severe post-operative circulatory failure (or grade III/IV shock) with a mean \pm SD estimated blood loss of $2.4 \pm 1.09$ Litres. Blood products transfused (mean $[\mathrm{SD}]=4.6$ [2.92] units) included $>4$ units of packed red blood cells (PRBC) in $29 \%$ cases, $>6$ units of fresh frozen plasma (FFP) in $3.2 \%$ cases, and $\geq 1$ unit of platelets (or whole blood) in $3.2 \%$ cases. On average, all patients received a minimum 4 units of PRBCs and 2 units of FFPs. The mean [SD] post-operative packed cell volume $\%$ (PCV \%) was 22.4 [4.96] \%.The median duration of hospital stay was 7 days (range $6-16$ ), with $77.4 \%$ having a $\leq 7$ day stay. Most patients (58\%) who underwent EPH had a healthy baby. 


\begin{tabular}{|c|c|}
\hline Variable $(\mathrm{N}=31)$ & Frequency (\%) \\
\hline \multicolumn{2}{|l|}{ Booking status } \\
\hline Unbooked & $21(67.7)$ \\
\hline Booked & $10(32.2)$ \\
\hline \multicolumn{2}{|l|}{ Type of Hysterectomy } \\
\hline Total & $25(80.6)$ \\
\hline Subtotal & $5(16.3)$ \\
\hline Near total & $1(3.2)$ \\
\hline \multicolumn{2}{|l|}{ Shock (grade III/IV) } \\
\hline No & $20(65)$ \\
\hline Yes & $11(35)$ \\
\hline Blood products received (units)*; Mean (SD) & $4.6 \pm 2.92$ \\
\hline PRBC (units); Mean (SD), Range & $4(2), 0-8$ \\
\hline$\leq 4$ & $22(71)$ \\
\hline$>4$ & $9(29)$ \\
\hline FFP (units); Mean (SD), Range & $1.83(2.68), 0-12$ \\
\hline$\leq 6$ & $30(96.8)$ \\
\hline$>6$ & $1(3.2)$ \\
\hline Platelets (units); Mean (SD), Range & $0.06(0.35), 0-2$ \\
\hline 0 & $30(96.8)$ \\
\hline 2 & $1(3.2)$ \\
\hline $\begin{array}{l}\text { Post-operative PCV (\%); Mean (SD) } \\
\end{array}$ & $22.4(4.96)$ \\
\hline Duration of hospitalization (days); Median & $7.0(6-16)$ \\
\hline (range) & $24(77.4)$ \\
\hline$\leq 7$ & $7(22.5)$ \\
\hline \multicolumn{2}{|l|}{$>7$} \\
\hline Variable $(\mathrm{N}=31)$ & Frequency (\%) \\
\hline \multicolumn{2}{|l|}{ Outcome of baby } \\
\hline Good & $18(58)$ \\
\hline Poor & $2(6.5)$ \\
\hline Died & $11(35.5)$ \\
\hline \multicolumn{2}{|c|}{$\begin{array}{l}\text { Table 5. Operative \& Post-Operative Details of Patients who } \\
\text { had Emergency Peripartum Hysterectomy }\end{array}$} \\
\hline $\begin{array}{l}{ }^{*} \text { All patients }(n=31) \text { required blood transfusion. } S D \\
\text { Caesarean section; PRBC, Packed red blood cells; } \mathrm{PC}\end{array}$ & $\begin{array}{l}\text { rd deviation; CS, } \\
\text { ed cell volume. }\end{array}$ \\
\hline
\end{tabular}

\section{DISCUSSION}

The present study provides an insight into the risk factors and complications of EPH performed in Eastern India. EPH remains a necessary technique for managing intractable obstetric haemorrhage. When to resort to this drastic step, has always been an obstetrician's dilemma, especially in a primigravida. Often a number of conservative approaches are undertaken before sacrificing her reproductive potential. Skill and assessment of one's own capability in undertaking such a major surgery should be prompt and immediate referral to a higher facility is the key as every second matters. With advancement in the medical management of $\mathrm{PPH}$, there is a changing trend noticed in the cause and incidence of EPH. In a 10-year review of EPH conducted in a hospital at Portugal, Carvalho et. al. pointed out that uterine atony, followed by placenta previa were the commonest indications for EPH.10 The risk was more with caesarean section, multiparity, maternal age and scarred uterus.

Shetty et al conducted a retrospective observational analytical study conducted at the Department of Obstetrics and Gynaecology, Lady Goshen hospital, Mangalore. They found a low incidence of EPH was 1.2/1000 deliveries. The main indications were uterine atony $4(66.7 \%)$, followed by rupture uterus $1(16.7 \%)$ and placenta previa with placenta accreta 1 (16.7\%). ${ }^{6}$ Dixit et al conducted a 12-month retrospective observational study at Department of Obstetrics and Gynaecology, Sri Aurobindo Institute of Medical Sciences, Indore, Madhya Pradesh (August 2016 to August 2017). They found EPH incidence rates at $2 / 1000$ (2/1500 following vaginal delivery and $2 / 500$ following caesarean section). Atonic postpartum haemorrhage (60\%) was the most common indication followed by placenta accreta $(20 \%)$ and uterine rupture $(20 \%)$. The most frequent sequelae were intensive care admissions (45\%) and post- operative pyrexia (27\%). ${ }^{7}$ A retrospective evaluation of cases of EPH during a 5-year period from 1999 at Department of Obstetrics and Gynaecology, Rajah Muthiah Medical College and Hospital, Annamalai University, Tamil Nadu, revealed EPH incidence rates of $0.2006 \%$. Rupture uterus was the commonest indication, while post-operative pyrexia was the commonest morbidity seen in $47.2 \%$ of cases; maternal mortality was $5.55 \% .^{8}$

In a 24-month study (Jan 2015 - Dec 2016) at Geetanjali Medical College and Hospital, Udaipur, 18 cases of EPH were analysed. The incidence of EPH was $0.52 \%$. Most common indications were atonic PPH (27.77\%), haemorrhagic shock (61.11\%) and bladder injury (27.11\%). ${ }^{9}$ A 5-year study conducted at Department of Obstetrics and Gynaecology, NRI Medical College and General Hospital, Guntur District, Andhra Pradesh, India revealed a EPH incidence rates of mere $0.18 \%$. The Incidence of hysterectomy following vaginal delivery was $0.04 \%$, and that following caesarean section was $0.29 \%$. Most of the patients were in the age group of $20-25$ yrs. (66.6\%). Atonic PPH (45.38\%) was again cited as the commonest indication. ${ }^{9}$ However, the incidence of 2.29/1000 deliveries in our study was higher. It was also much higher than that reported by D'Arpe $S$ et al., (2.2/1000), Singhla A et al.,(1.92/1000),Dixit(2/1000), but lower than that reported by Khan B et al., (10.52/1000).(5658). The incidence rates are also much higher in comparison those of the developed countries like UK and Nordic countries. ${ }^{11}$

In our present study, $93.6 \%$ of the women had at least one prior caesarean section. This is in agreement with most previous studies from various parts of the world which found $50 \%$ to $83 \%$ of the women who underwent EPH had a prior caesarean section. The United Kingdom Obstetric Surveillance Study (UKOSS) which was population based study, had also concluded that the risk of an EPH rises with increasing number of previous caesarean sections. ${ }^{11}$ In our study, multivariate logistic regression revealed that a previous caesarean section (odds-ratio, OR $[95 \% \mathrm{CI}]=91.80$ (3.75 - 2246.52) $\mathrm{p}=0.005]$ was a significant predictor of maternal mortality. Similar findings were reflected in a systematic review and meta-analysis $(n=7,858)$, that revealed a (previous) caesarean delivery is associated with a higher risk of EPH. Recently, a study from Department of Obstetrics and Gynaecology, Fujian Provincial Maternity and Children's Hospital has found that caesarean deliveries were associated with an increased risk of EPH. ${ }^{12}$ However, in our study, the mode of delivery was not a significant predictor of maternal or neonatal morbidity. The most common type of child birth preceding the EPH was a caesarean section $(96.8$ $\%$ ) rather than a vaginal delivery, as was the case with majority of studies. ${ }^{12}$ The perinatal mortality was also high in our study (35.5\%), which resembles the findings other studies which reported rates of $37 \%$ to $64 \%$. Commonest indication of EPH in our study was morbid adherent placenta (83.2\%). The incidence of abnormal placenta was higher in comparison to previous Indian studies by Singhla $\mathrm{A}$ et al. (15.46\%), and Singh and Nagrath (27.45\%), respectively. Other indications for EPH in our study included uterine atony (3.2\%), abruptio placentae (3.2\%), broad ligament haematoma $(3.2 \%)$, uterine rupture $(3.2 \%)$. Incidence of bladder injury $(6.4 \%)$ was similar to that of Singhla A et. al (6.7\%) and Anita and Kavita (7.3\%).6 Perinatal mortality was 
$35.5 \%$ in contrast to $30.43 \%$ and $85.71 \%$ reported by Singhla et al. and Singh et al., respectively. ${ }^{6}$

Maternal mortality rate in our study was $13 \%$. This was mainly attributed to haemorrhagic shock (35\%) in the postoperative setting, as reported in previous studies. ${ }^{10}$ Infact, post-operative grade III/IV shock was also a statistically significant predictor of maternal deaths in our study. With increasing rates of caesarean section and its associated rise in placenta previa and placenta accreta, the incidence of EPH is expected to rise world over. Regular audits are needed to curb the caesarean section rates and its accompanying complications. Careful antenatal assessment and early recognition of risk factors for haemorrhage should be accompanied by arrangements for adequate uterotonics and blood products for early resuscitation. The threshold for performing an EPH will depend on haemodynamic stability of the patient and the surgical expertise of the obstetrician with regard to conservative procedures like B-Lynch sutures, uterine and internal iliac artery ligation. Early intervention by a senior experienced obstetrician well versed with conservative measures to preserve the uterus where possible may prevent an overzealous inexperienced surgeon attempting an EPH. Subtotal EPH may be a better choice when surgery needs to be completed in a shorter time before the onset of haemodynamic instability. The complications following EPH like ICU admission and need for blood transfusions are also mostly due to the underlying haemorrhage. However, urological injuries, febrile morbidity, wound infection, prolonged hospital stay, due to the EPH is influenced by technique and skill of operating surgeon, availability of blood products, adequate antibiotic cover and intensive care management. Performance of EPH by an experienced surgeon is reported to significantly reduce the operating time, number of units of blood transfusion and hospital stay. An informed consent regarding the possibility of EPH and ensuring the availability of consultants while managing a high risk parturient can prevent mortality. Although, EPH marks an abrupt end to the reproductive career of a woman, it is an acceptable alternative where expertise or facilities for more complex modalities of management, such as uterine artery embolisation may not be available.

\section{Limitations}

The only limitations of this study are its retrospective nature and small sample, which undermine the generalizability of the results. Nevertheless, the study data indicates that rate of EPH in our institution is high. A previous CS, abnormal placenta qualify as important pre-operative risk factors for EPH. Post-operative shock is associated with poor outcome.

\section{CONCLUSIONS}

Although no risk assessment system can predict all instances where caesarean delivery will be needed, a significant percentage of patients who are at high risk for severe haemorrhage and the subsequent need of EPH can be identified before surgery. Our data reflects that the preoperative risk factors like a previous history of CS and abnormal placentation need extra vigilance. Post-operative circulatory failure should be promptly handled with inotrope support. The presence of such risk factors should facilitate consultation, referral or transfer of patients before surgery to a tertiary care facility.

\section{REFERENCES}

[1] Park EH, Sachs BP. Postpartum haemorrhage and other problems of third stage. $2^{\text {nd }}$ edn. Philadelphia, Pa, USA: W.B. Saunders 1999: p. 1231-46.

[2] Jin R, Guo Y, Chen Y. Risk factors associated with emergency peripartum hysterectomy. Chin Med J 2014;127(5):900-4.

[3] Gurtani FM, Fadaei B, Akbari M. Emergency peripartum hysterectomy in Isfahan: maternal mortality and morbidity rates among the women who underwent peripartum hysterectomy. Adv Biomed Res 2013;2:20.

[4] Machado LS. Emergency peripartum hysterectomy: incidence, indications, risk factors and outcome. N Am J Med Sci 2011;3(8):358-61.

[5] Kwame-Aryee R, Kwakye A, Seffah J. Peripartum hysterectomies at the korle-bu teaching hospital: a review of 182 consecutive cases. Ghana Medical Journal 2007;41(3):133-8.

[6] Joana FC, Adelaide C, S'́lvia T, et al. Emergency peripartum hysterectomy: a 10-year review. Article ID 721918, International Scholarly Research Network ISRN Emergency Medicine 2012;2012:1-7.

[7] Ozden S, Yildirim G, Basaran T, et al. Analysis of 59 cases of emergent peripartum hysterectomies during a 13 year period. Archives of Gynaecology and Obstetrics 2005;271(4):363-7.

[8] Nasrat HA, Yuoussaef MH, Mazoogi A, et al. "Near miss" obstetric morbidity in an inner city hospital in Saudi Arabia, East Meditarr Health J 1999;5(4):717-26.

[9] Fatima M, Kasi PM, Baloch SN, et al. Experience of emergency peripartum hysterectomies in a tertiary care hospital in Quetta, Pakistan. Article ID 854202, ISRN Obstetrics and Gynecology 2011;2011:1-4.

[10] Yamani-Zamzami TY. Indication of emergency peripartum hysterectomy: review of 17 cases. Archives of Gynecology and Obstetrics 2003;268(3):131-5.

[11] Bai SW, Lee HJ, Cho JS, et al. Peripartum hysterectomy and associated factors. Journal of Reproductive Medicine 2003;48(3):148-52.

[12] Obiechina NJ, Eleje GU, Ezebialu IU, et al. Emergency peripartum hysterectomy in Nnewi, Nigeria: a 10-year review. Nigerian Journal of Clinical Practice 2012;15(2):168-71. 